\title{
Study of PLGA microspheres loaded with p0sx/PEl nanoparticles for repairing bone defects in vivo and in vitro
}

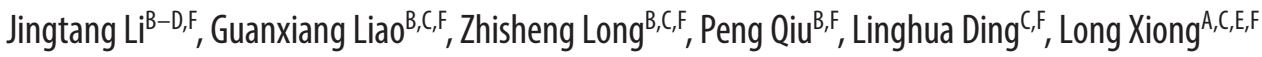 \\ Department of Orthopedics, Jiangxi Provincial People's Hospital Affiliated to Nanchang University, China \\ A - research concept and design; B - collection and/or assembly of data; $C$ - data analysis and interpretation; \\ $D$ - writing the article; $E$ - critical revision of the article; $F$ - final approval of the article
}

Address for correspondence

Long Xiong

E-mail: xionglong1234@126.com

\section{Funding sources}

This study was supported by Jiangxi Provincial Youth Fund (20161BAB215258) and the general plan of Jiangxi Provincial Department of Health (№. 20165030)

Conflict of interest

None declared

Received on March 29, 2019

Reviewed on 0ctober 1, 2019

Accepted on January 21, 2020

Published online on May 4, 2020

Cite as

Li J, Liao G, Long Z, Qiun P, Ding L, Xiong L. Study of PLGA

microspheres loaded with p0sx/PEl nanoparticles for

repairing bone defects in vivo and in vitro. Adv Clin Exp Med.

2020;29(4):431-440. doi:10.17219/acem/116752

DOI

10.17219/acem/116752

Copyright

Copyright by Author(s)

This is an article distributed under the terms of the

Creative Commons Attribution 3.0 Unported (CC BY 3.0)

(https://creativecommons.org/licenses/by/3.0/)

\section{Abstract}

Background. Autogenous or allogenic bone transplantation is the main treatment for bone defects and nonunions. However, the shortcomings of autogenous or allogenic bone transplantation limit its wide application in clinical use.

Objectives. This study investigated the effect of poly(lactic-co-glycolic acid) (PLGA) microspheres loaded with p0sterix (p0sx)/polyethylenimine (PEI) nanoparticles in repairing bone defects and explored its mechanism.

Material and methods. Poly(lactic-co-glycolic acid) microspheres loaded with p0sx/PEI nanoparticles were constructed. The Osx transfection effect was detected by fluorescence quantitative PCR and western blotting methods. 3-(4,5)-dimethylthiahiazo (-z-y1)-3,5-di- phenytetrazoliumromide (MTT) and flow cytometry methods were used to detect cell proliferation. The collagen I (Col-1), osteopontin (OPN) and osteocalcin (OC) expression levels were detected using real-time polymerase chain reaction (RT-PCR) and western blotting methods. Bone defect model was constructed. Bone repair was detected using X-ray, hematoxylin and eosin (H\&E) staining, and Mason staining methods.

Results.PLGA@p0sx/PEl has transfection effect both in vitro and in vivo, does not affect cell proliferation and is safe for cells. PLGA@pOsx/PEl could promote the expression of Col-1, OPN and OC in vitro and in vivo. PLGA@p0sx/PEl could promote osteogenesis in vivo.

Conclusions.PLGA@pOsx/PEl with high Osx expression could promote the expression of OC, OPN, and COL-I. PLGA@p0sx/PEl can be used as a material for repairing bone defects and can promote bone formation. These results provide a theoretical and practical basis for its further clinical application.

Key words: bone defect, p0sx/PEl nanoparticles, PLGA microspheres 


\section{Introduction}

Autogenous or allogenic bone transplantation is the main treatment for bone defects and nonunions in clinical practice. However, the shortcomings of autogenous or allogenic bone transplantation limit its wide application. ${ }^{1-4}$ Bone repair using bone tissue engineering technology is a possible way to solve the problem of bone defect treatment. ${ }^{5-8}$ There are 2 kinds of bone tissue engineering techniques: in vivo and in vitro. In vitro bone tissue engineering technology has several shortcomings, which limits its application. Firstly, the construction is complex and expensive with a long operating cycle; it does great damage to patients. Secondly, the proportion of bone marrow mesenchymal stem cells to bone marrow cells in elderly patients decreases correspondingly, the cell proliferation rate decreases and the osteogenesis ability in vivo decreases significantly. Thirdly, exogenous osteogenic factors are easily lost and inactivated in vivo with short duration, low potency and high cost; it may induce an immune response., ${ }^{9,10}$

Bone morphogenetic protein 2 (BMP-2) is a classic bone growth factor. ${ }^{11,12}$ In BMP-2 promoting osteogenesis signaling pathway, Nakashima et al. found transcription factor Osterix (Osx) in mice in 2002. ${ }^{13}$ Osterix is a highly specific transcription factor of osteoblasts located downstream of BMP-2. Bone morphogenetic protein 2 promotes osteogenesis through Osx. Osterix regulates the expression of many important late phenotypes and functional proteins of osteoblasts, such as collagen I, osteopontin, salivary protein and osteocalcin, and synthesizes matrix to produce mineralization reaction to achieve bone formation. Osterix has zinc finger structure and is a specific transcription factor of osteoblasts. Osterix is expressed in all osteoblasts. Bone morphogenetic protein 2 has a positive regulation on $O s x$ in the process of osteoblasts differentiation. Osterix is one of the most important transcription factors found to regulate osteoblast differentiation, and its expression level is used as a marker for osteoblast differentiation. At the same time, Osx can promote the differentiation of preosteoblasts into mature and functional osteoblasts. Osterix has the most specific effect on bone formation. ${ }^{14-16}$ There would be no bone formation and regeneration without Osx. ${ }^{17-19}$

Vectors that can be used to transfer therapeutic genes into target cells include viral and non-viral vectors. However, viral vectors have a limited size and number of genes, poor targeting specificity, and many undesirable side effects. ${ }^{20,21}$ Nanotechnology has created a new non-viral vector system, in which polyethylenimine (PEI) is an effective cationic carrier with high gene transfection rate and low adverse reactions. ${ }^{22-26}$ Polyethylenimine nanoparticles have been used as Osx plasmid (pOsx) carriers. Although they are beneficial to cell binding, uptake and transfection, pOsx/PEI nanoparticles are easily degraded and destroyed by tissue fluids. In order to make pOsx/PEI nanoparticles release slowly in the bone defect area and be effective for a longer period of time, we are looking for a drug sustained-release carrier, poly(lactic-co-glycolic acid) (PLGA), which is biodegradable, is a good membrane slow-release carrier and promotes bone growth. ${ }^{27}$ PLGA@ pBMP-2/PEI nanoparticles were successfully used to transfect cells and promote osteoblast differentiation. ${ }^{28}$

There are few reports on the use of Osx in the treatment of bone defects. In this study, PLGA microspheres were successfully prepared to encapsulate pOsx/PEI nanoparticles. Bone regeneration, bone repair ability and excessive osteogenesis of PLGA microspheres were studied in cell and animal models. The related mechanisms were studied to provide a theoretical basis for its clinical application and to open up a new treatment method for bone defects.

\section{Material and methods}

\section{Experimental cells and animals}

The mouse osteoblastic cell line MC3T3-E1 cells were purchased from Beijing Beina Biological Technology Co., Ltd. (Beijing, China) (BNCC339285). MC3T3-E1 cells were cultured in $\alpha$-MEM containing 10\% fetal bovine seum (FBS) and $1 \%$ penicillin-streptomycin (Hyclone, Logan, USA) in a humidified, $95 \%$ air, $5 \% \mathrm{CO}_{2}$ atmosphere at $37^{\circ} \mathrm{C}$. They were divided into control group, PLGA@PEI group (transfected with $10 \mu \mathrm{L}$ PLGA@PEI suspension for 7 days), and PLGA@pOsx/PEI group (transfected with $10 \mu \mathrm{L}$ PLGA@ pOsx/PEI suspension for 7 days).

Japanese big-ear rabbits were purchased from Nanchang Longping Rabbit Industry Co., Ltd. (Nanchang, China). They were maintained in a temperature-controlled room $\left(22-26^{\circ} \mathrm{C}\right)$ with 12 -h light/dark cycles, with continuous access to food and water. All animal experiments were conducted according to the Principles of Laboratory Animal Care (National Society for Medical Research in China).

\section{Experimental reagents and instruments}

Poly(lactic-co-glycolic acid) (P133293, Aladdin); PEI (408727, sigma); PVA (P105126, Aladdin); DMEM Completely High Sugar Culture Medium (NanJing KeyGen Biotech Co., Ltd. KGM12800S-500); Cell Cycle Staining Kit (CCS102, MultiSciences (Lianke) Biotech Co., Ltd.); Mouse ALP biochemical detection Kit (A059-2, NanJing Jiancheng bioengineering Institute); Trizon Reagent (CW0580S, Beijing ComWin Biotech Co.,Ltd.); Ultrapure RNA extraction kit (CW0581M, Beijing ComWin Biotech Co.,Ltd.); HiFiScript cDNA synthesis Kit (CW2569M, Beijing ComWin Biotech Co.,Ltd.); UltraSYBR Mix (CW0957M, Beijing ComWin Biotech Co.,Ltd.); RIPA Cell lysis buffer (C1053, Beijing Applygen Co.,Ltd.); PVDF membrane (IPVH00010, Millipore); Hypersensitive luminescent liquid (RJ239676, Thermo Fisher); Mouse Monoclonal AntiGAPDH (TA-08, Beijing ZSGB-BIO Co.,Ltd.); Horseradish Enzyme Labeled Goat Anti-Rat IgG (H+L) (ZB-2305, Beijing 
ZSGB-BIO Co.,Ltd.); Rabbit Polyclonal Anti-Osteocalcin (OC) (OM266698, OmnimAbs, 1/500); Rabbit Polyclonal Anti-Osteopontin (OPN) (AF0227, Affinity, 1/500); Rabbit Polyclonal Anti-Collagen I (Cbfet1) (bs-0578R, Bioss, 1/100); Rabbit Polyclonal Anti-Osterix (Osx) (bs-1110R, Bioss, 1/100); Masson's Trichrome Stain Kit (G1340, Solarbio); NovoCyte ${ }^{\mathrm{TM}}$ Flow cytometry (NovoCyte 2060R, ACEA Hangzhou Biosciences Inc.); Microplate Reader (RT-6100, Rayto); fluorescent quantitative PCR instrument (CFX Connect ${ }^{\mathrm{TM}}$, Bio-Rad Shanhhai Laboratories); Protein vertical electrophoresis instrument (DYY-6C, Beijing 61 instrument factory); Ultra High Sensitivity Chemiluminescence Imaging System (Chemi DocTM XRS+, Bio-Rad Shanhhai Laboratories); Microscope (CX41 Olympus); Paraffin slicer for biological tissues (BQ-318D, Hubei Bona Medical Technology Co., Ltd.).

\section{Preparation of PLGA@PEI and PLGA@ pOsx/PEl microspheres}

Polyvinyl alcohol (PVA) solution (6\%) was prepared, $200 \mathrm{mg}$ PLGA was dissolved in $10 \mathrm{~mL}$ dichloromethane solution by double emulsion solvent evaporation method. Osterix vector $(180 \mu \mathrm{g})$ and PEI $(191.25 \mu \mathrm{g}, \mathrm{N} / \mathrm{p}=8)$ were dissolved in $3 \mathrm{~mL}$ water. The $3 \mathrm{~mL}$ vector complex was added to the above PLGA solution and stirred for $10 \mathrm{~s}$ at 5,000 rpm with a hand-held homogenizer to form colostrum solution. Colostrum solution was quickly poured into 3\% PVA solution $(10 \mathrm{~mL})$, and stirred at 10,000 rpm under ice bath for $10 \mathrm{~s}$ to form double emulsion solution. The double emulsion solution was poured into $500 \mathrm{~mL}$ of $0.5 \%$ PVA solution and stirred by magnetic force for $2 \mathrm{~h}$ at room temperature. The residual organic solvents were removed by vacuum distillation after $6 \mathrm{~h}$ and centrifuged at 5,000 rpm for $15 \mathrm{~min}$. Poly(lacticco-glycolic acid) microspheres loaded with pOsx/PEI powders were obtained by deionized water washing 3 times and freeze-drying of precipitation. They were stored at $4^{\circ} \mathrm{C}$. The blank PLGA microspheres and the PLGA microspheres containing only PEI were prepared using the same method.

\section{Cell transfection}

MC3T3-E1 cells were pre-incubated with $\alpha$-MEM containing 10\% FBS overnight in 6-well plates at a density of $5 \times 10^{5}$ cells per well. The microspheres could be transfected when the cells adhered completely.

The microsphere suspension prepared in advance was placed in the water-bath ultrasound instrument for 10-20 min, and the microsphere suspension was added to 6 -well plates after it was fully dispersed $(10 \mu \mathrm{L} /$ well $)$.

\section{MTT detection}

Cell viability was determined by MTT reduction assay. In brief, MC3T3-E1 cells transfected with microspheres for 7 days in each group were digested with $0.25 \%$ tryptase (containing $0.02 \%$ EDTA) and collected respectively.
They were preincubated with $\alpha$-MEM containing $10 \%$ FBS overnight in 96-well plates at a density of $5 \times 10^{3}$ cells per well. According to the experimental design, cells in each well were added $10 \mu \mathrm{L}$ of MTT without light. The cells were incubated at $37^{\circ} \mathrm{C}$ for $4 \mathrm{~h}$, the supernatants were removed, and the formazan crystals were dissolved in $100 \mu \mathrm{L}$ of dimethyl sulfoxide (DMSO). Absorbance was recorded at a wavelength of $490 \mathrm{~nm}$ and reference wavelength of $630 \mathrm{~nm}$ using a microplate reader (Bio-Rad, Foster, USA).

\section{Detection of cell cycle by flow cytometry}

Cell suspension was centrifuged at 2,500 rpm for $3 \mathrm{~min}$ and the supernatant was discarded. The precipitation was fixed with $1 \mathrm{~mL}$ absolute ethanol for more than $2 \mathrm{~h}$ at $4^{\circ} \mathrm{C}$, centrifuged with $8,000 \mathrm{rpm}$ for $3 \mathrm{~min}$, and the supernatant was discarded. The precipitation was washed with phosphate-buffered saline (PBS) and stained with $1 \mathrm{~mL}$ DNA staining solution at room temperature for $30 \mathrm{~min}$. The cells were detected and analyzed by flow cytometry.

\section{Alkaline phosphatase activity detection}

MC3T3-E1 cells were treated with the indicated agents according to the experimental design. Alkaline phosphatase (ALP) activity was detected using ALP activity detection Kit according to the manufacturer's instructions. The values of OD at $520 \mathrm{~nm}$ were determined using enzyme-labeled instrument.

\section{Construction of repairing bone defect of rabbit model}

Rabbits were weighed and injected with $1 \%$ sodium pentobarbital at a dose of $30 \mathrm{mg} / \mathrm{kg}$ through an ear vein. The rabbit was fixed on the operating table with its forelimb hair removed and the operation area was wiped with iodophor 3 times. A towel was spread at the start of the operation. The skin was incised with a blunt separation of muscles, the radius was exposed and a defect of about $1.5 \mathrm{~cm}$ in length was created in the middle part of the radius. PLGA@pOsx/PEI and PLGA@PEI microspheres were filled into the bone defect site and sutured layer by layer. Penicillin (80,000 units per day) was injected intramuscularly 3 days after operation, and the wound was observed for any signs of infection. The rabbits were divided into the Model group, the PLGA group, the PLGA@PEI group, and the PLGA@pOsx/PEI group. Bone repair was detected using X-ray after 60 and 90 days, and bone defect repair tissues were taken for detection.

\section{RNA extraction and qRT-PCR}

The total RNA was extracted using Ultrapure RNA kit according to the manufacturer's protocol. Total RNA $(1 \mu \mathrm{g})$ was subjected to reverse transcription using HiFiScript 
Table 1. Primers used in this study

\begin{tabular}{|l|c|c|c|}
\hline \multirow{2}{*}{ Gene } & Primers $\left(5^{\prime}-3^{\prime}\right)$ & $\begin{array}{c}\text { Product } \\
\text { length } \\
\text { [bp] }\end{array}$ & $\begin{array}{c}\text { Annealing } \\
\text { temperature } \\
{\left[{ }^{\circ} \mathrm{C}\right]}\end{array}$ \\
\hline Osx & $\begin{array}{l}\text { F: GGGAAAGGAGGCACAAAG } \\
\text { R: AGGAAATGAGTGAGGGAAGG }\end{array}$ & 174 & 56.0 \\
\hline OPN & $\begin{array}{c}\text { F: CTGATGAGACCGTCACTGCT } \\
\text { R: TGCCCTTTCCGTTGTTG }\end{array}$ & 273 & 57.3 \\
\hline OC & $\begin{array}{c}\text { F: GGAGGGCAATAAGGTAGTGAA } \\
\text { R: CCATAGATGCGTTTGTAGGC }\end{array}$ & 162 & 56.8 \\
\hline Col-1 & $\begin{array}{c}\text { F: CTACTCAGCCGTCTGTGCCT } \\
\text { R: GCTTCTTTTCCTTGGGGTT }\end{array}$ & 63 & 58.6 \\
\hline GAPDH & $\begin{array}{c}\text { F: GCAAGTTCAACGGCACAG } \\
\text { R: CGCCAGTAGACTCCACGAC }\end{array}$ & 141 & 58.0 \\
\hline
\end{tabular}

cDNA synthesis Kit. Real-time polymerase chain reaction (RT-PCR) were performed using SYNBR Green PCR Master Mix. At the end of each reaction, a melting curve analysis was performed to confirm the absence of primer dimmers. Glyceraldehyde 3-phosphate dehydrogenase $(G A P D H)$ gene was used as an internal control for normalization of RNA quantity and quality differences in all samples. Quantifications of target genes mRNA was performed using the $2-\Delta \Delta \mathrm{Ct}$ method. Primers' sequences were listed in Table 1.

\section{Western blotting method}

The cells were lysed with lysis solution (Sigma-Aldrich, St. Louis, USA) at $4^{\circ} \mathrm{C}$ overnight. They were centrifuged with $10,000 \mathrm{rpm} / \mathrm{min}$ at $4^{\circ} \mathrm{C}$ for $10 \mathrm{~min}$. The supernatant was collected. Total proteins were extracted and the protein concentration was determined using BCA Protein Assay Kit. Proteins (50 $\mu$ g per lane) were separated using $12 \%$ sodium dodecyl sulfate and polyacrylamide gel electophoresis (SDS-PAGE). Proteins were then electrotransferred to a polyvinylidene fluoride (PVDF) membrane (Amersham Biosciences, Piscataway, USA). The PVDF membrane was rinsed with Tris buffered saline (TBS) for 10-15 min, placed in TBS/T blocking buffer containing $5 \%(\mathrm{w} / \mathrm{v})$ of skimmed milk powder and incubated at room temperature for $2 \mathrm{~h}$ following the addition of an appropriate dilution of primary antibodies. The membrane was then 3 times rinsed with TBST (5-10 min/wash) and then incubated at room temperature for $1 \mathrm{~h}$ with horseradish peroxidase-labeled secondary antibody (1:50,000; Abcam, Cambridge, UK; diluted with TBST containing 0.05\% (w/v) skimmed milk powder). The membrane was then rinsed 3 times with TBST (5-10 min/wash). Protein bands were detected using an enhanced chemiluminescence kit (Perkin-Elmer Inc., Waltham, USA) and quantified as the ratio to GAPDH. Quantification was performed using Quantity One software (Bio-Rad Laboratories, Inc., Hercules, USA).

\section{Hematoxylin and eosin staining test}

The tissues were taken and washed with PBS, fixed with $4 \%$ paraformaldehyde solution and embedded in paraffin. They were cut into $5-\mu \mathrm{m}$ slices and stained with hematoxylin and eosin (H\&E) using conventional method. The sections were deparaffinized with 2 changes of xylene, 10 min each; they were re-hydrated in 2 changes of absolute alcohol, 5 min each; 95\% alcohol for $2 \mathrm{~min}$ and $70 \%$ alcohol for $2 \mathrm{~min}$; they were washed briefly in distilled water and stained in Harris hematoxylin solution for $8 \mathrm{~min}$, washed in running tap water for $5 \mathrm{~min}$, differentiated in $1 \%$ acid alcohol for $30 \mathrm{~s}$, washed in running tap water for $1 \mathrm{~min}$ and blued in $0.2 \%$ ammonia water or saturated lithium carbonate solution for $30 \mathrm{~s}-1 \mathrm{~min}$, washed in running tap water for $5 \mathrm{~min}$, rinsed in 95\% alcohol, 10 dips; counterstained in eosin-phloxine solution for $30 \mathrm{~s}-1 \mathrm{~min}$ and dehydrated in 95\% alcohol, 2 changes of absolute alcohol, 5 min each. They were cleared in 2 changes of xylene, 5 min each and mounted with xylene based mounting medium. The samples were observed under an optical microscope.

\section{Masson staining test}

The tissues were washed with running water and dehydrated with $70 \%, 80 \%$ and $90 \%$ ethanol solutions, respectively. They were treated with mixtures of equivalent pure alcohol and xylene for $15 \mathrm{~min}$, xylene I for $15 \mathrm{~min}$ and II for $15 \mathrm{~min}$ (until transparent). They were put in the mixture of xylene and paraffin for $15 \mathrm{~min}$, then put in paraffin I and paraffin II for 50-60 min, respectively. The paraffin embedding tissues were sliced and stained using Masson's Trichrome Stain Kit (Solarbio, Beijing, China) according to the manuals.

\section{Statistical analysis}

The data was analyzed using the IBM SPSS Statistics for Windows v. 19.0 software (IBM Corp., Armonk, USA). The normality of probability distribution was approved using Kolmogorov-Smirnov test. One-way analysis of variance (ANOVA) and t-test were used for comparison between groups. A p-value $<0.05$ was considered to indicate a statistically significant difference.

\section{Results}

\section{Cell transfection efficiency}

Compared with the control group, the expression in Os $x$ in the PLGA@pOsx/PEI group was significantly higher than that in the control group (Fig. 1, mRNA expression $\mathrm{p}=0.003$, protein expression $\mathrm{p}=0.021$ ). 


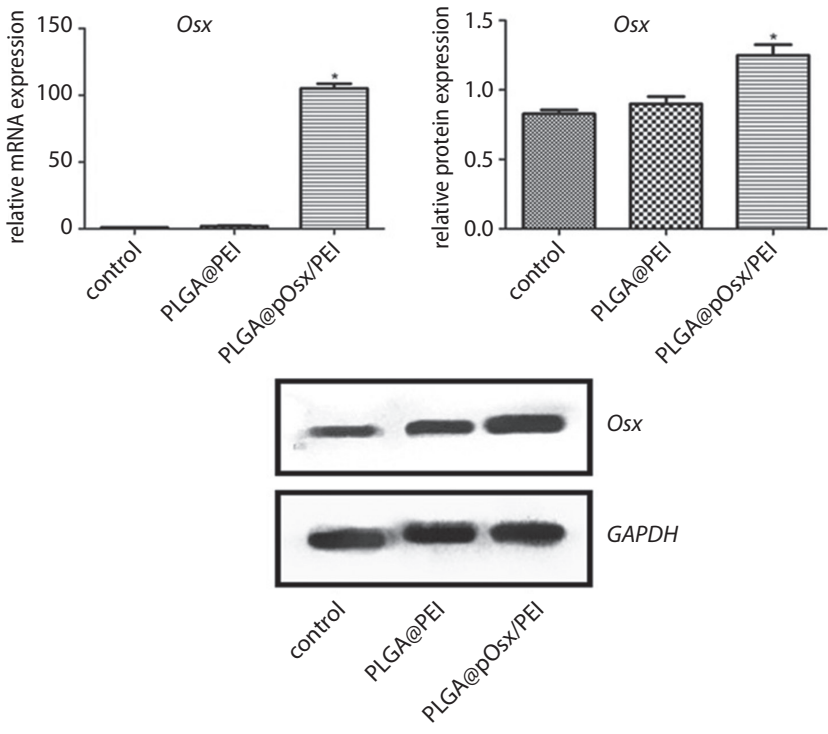

Fig. 1. Validation of cell transfection efficiency

*mRNA expression $(p=0.003)$ and protein expression $(p=0.021)$ vs control.

\section{Effects of PLGA@pOsx/PEI on cell proliferation}

As shown in Fig. 2, compared with the control group, there was no significant difference in cell proliferation and cell cycle in other groups.

\section{Effect of PLGA@pOsx/PEl on cell osteogenesis}

As shown in Fig. 3A, ALP activity in the PLGA@pOsx/ PEI group was significantly higher than in the control group ( $\mathrm{p}=0.027)$. As shown in Fig. 3B, the expression levels of Col-1, OPN and OC in the PLGA@pOsx/PEI group were significantly higher than those in the control group $(\mathrm{p}=0.009)$.

\section{Osterix expression in vivo}

As shown in Fig. 4, compared with the model, the mRNA expression of Osx in the PLGA@pOsx/PEI group increased significantly at $60(\mathrm{p}=0.037)$ and 90 days $(\mathrm{p}=0.004)$, the Osx protein expression in the PLGA@pOsx/PEI group also increased significantly at $60(\mathrm{p}=0.017)$ and 90 days $(\mathrm{p}=0.012)$.
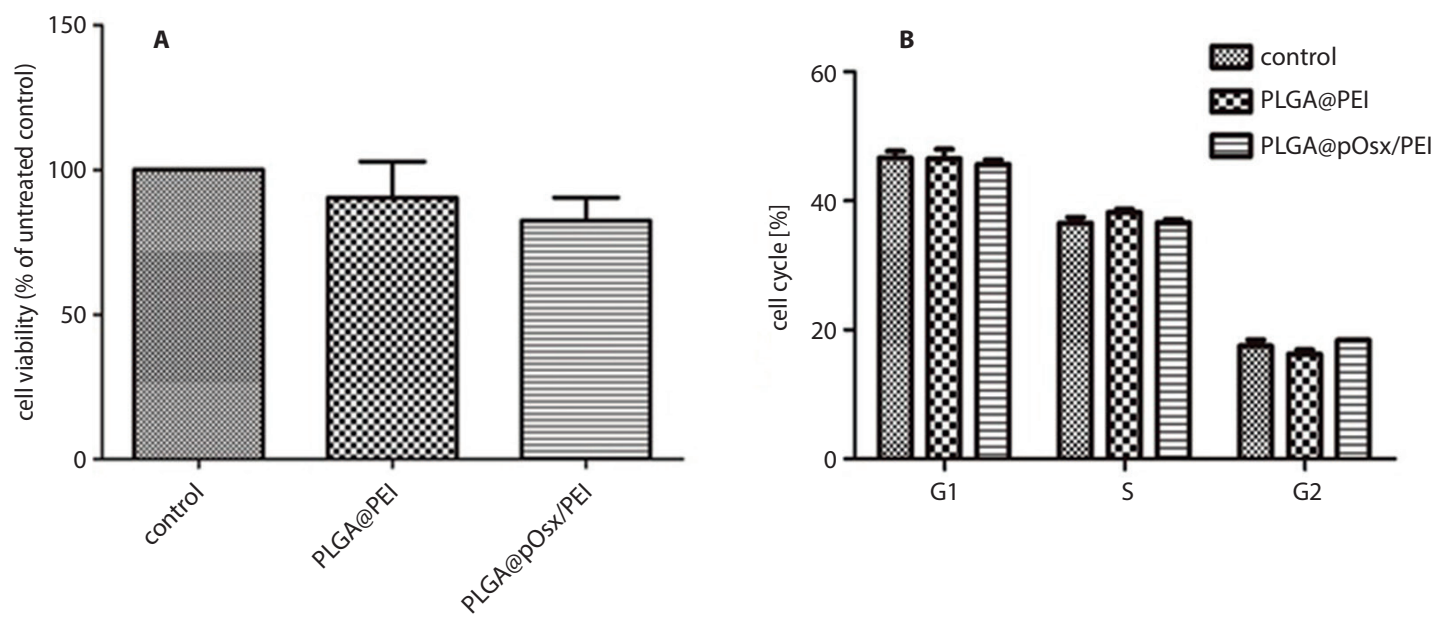

Fig.2.PLGA@

pOsx/PEl had no

effects on cell

proliferation

A - results of cell proliferation;

$B$ - results of cell

cycles.
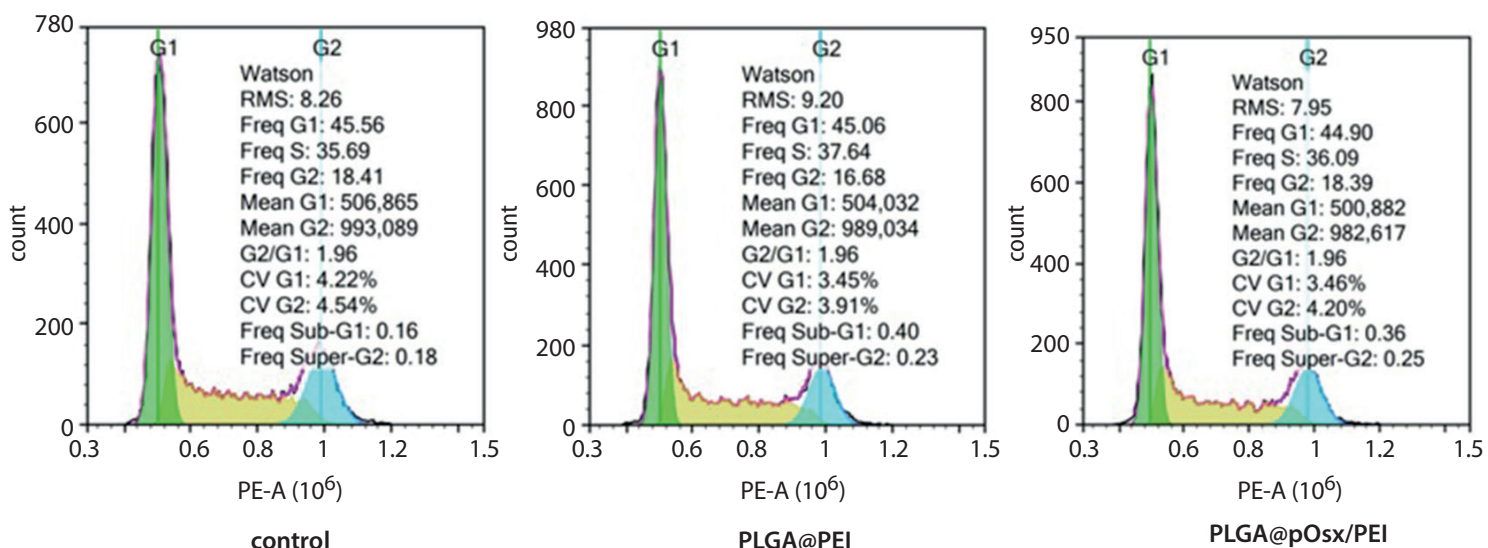
A
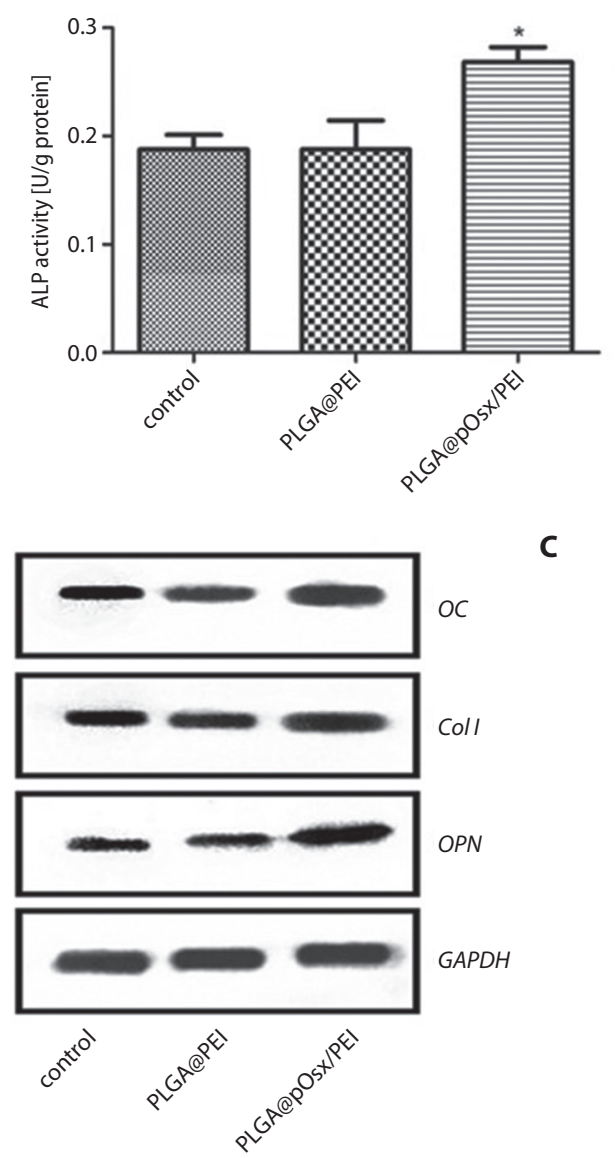

C

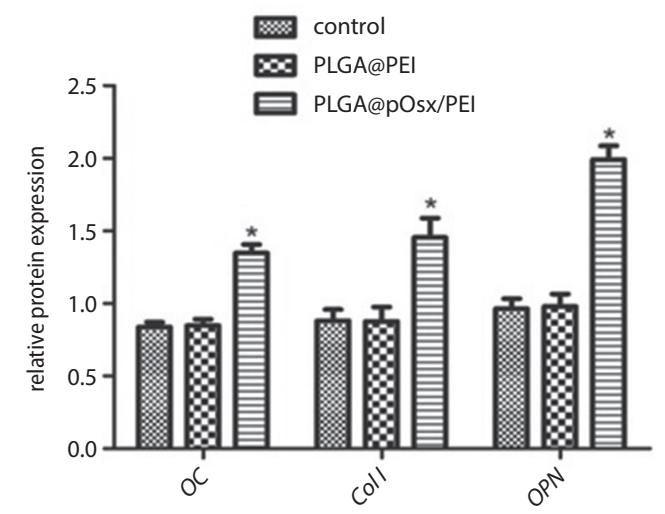

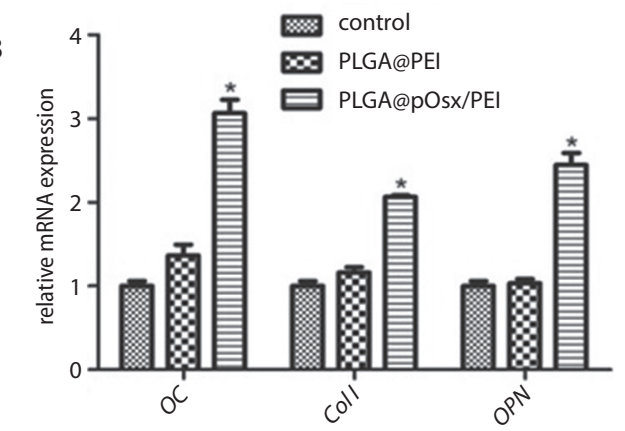

Fig. 3. Effect of PLGA@pOsx/PEI on cell osteogenesis

A - ALP activity in different groups ( ${ }^{*} p=0.027$ vs control); B, C - Col-I, $O P N$ and $O C$ expression levels in different groups ( ${ }^{*} p=0.009$ vs control).
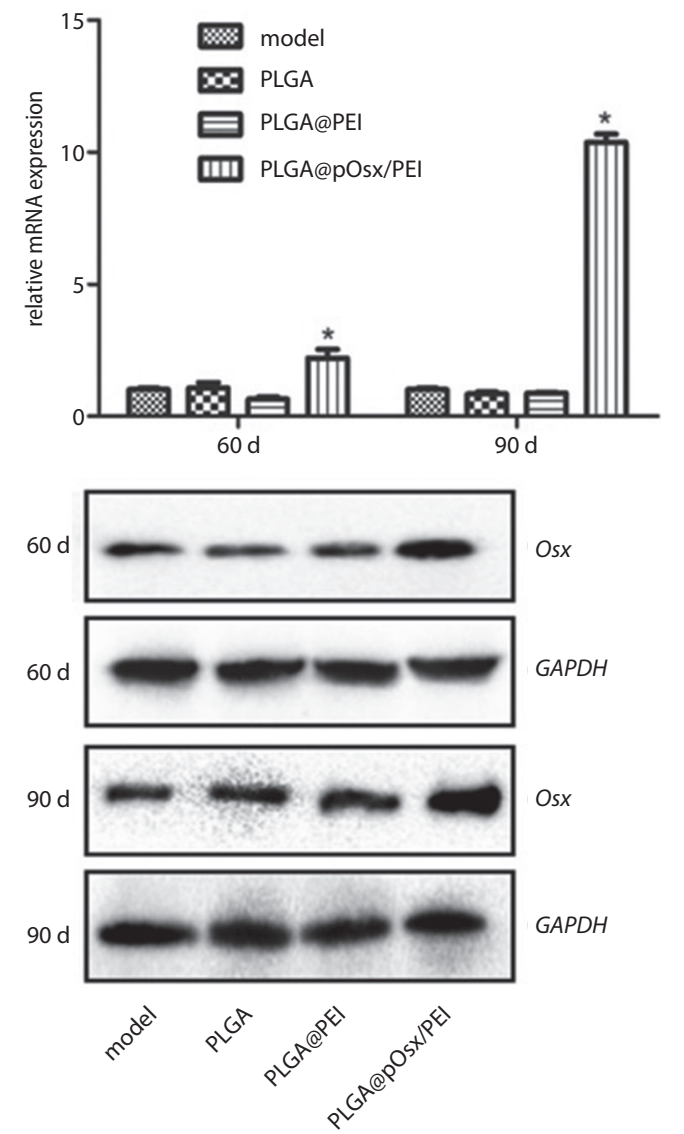

Fig. 4. Osx expression in vivo

Compared with that of the model group, the mRNA expression of Osx in the PLGA@ pOsx/PEl group increased significantly at 60 $(p=0.037)$ and 90 days $(p=0.004)$, the Osx protein expression in the PLGA@ pOsx/PEl group also increased significantly at 60 $(p=0.017)$ and 90 days $(p=0.012)$.

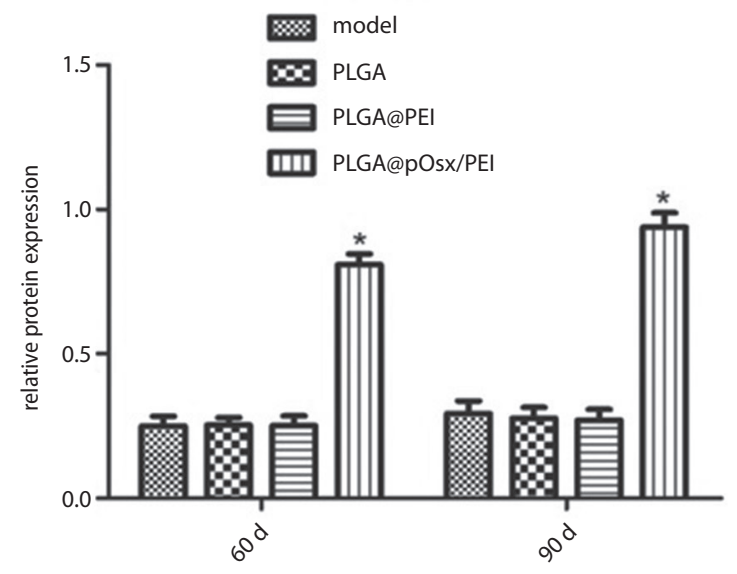


A

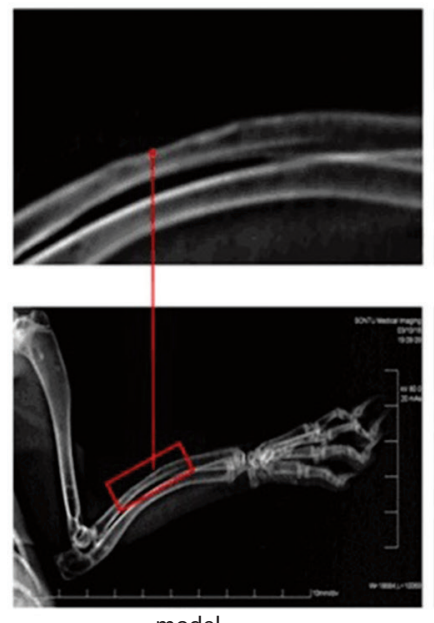

model
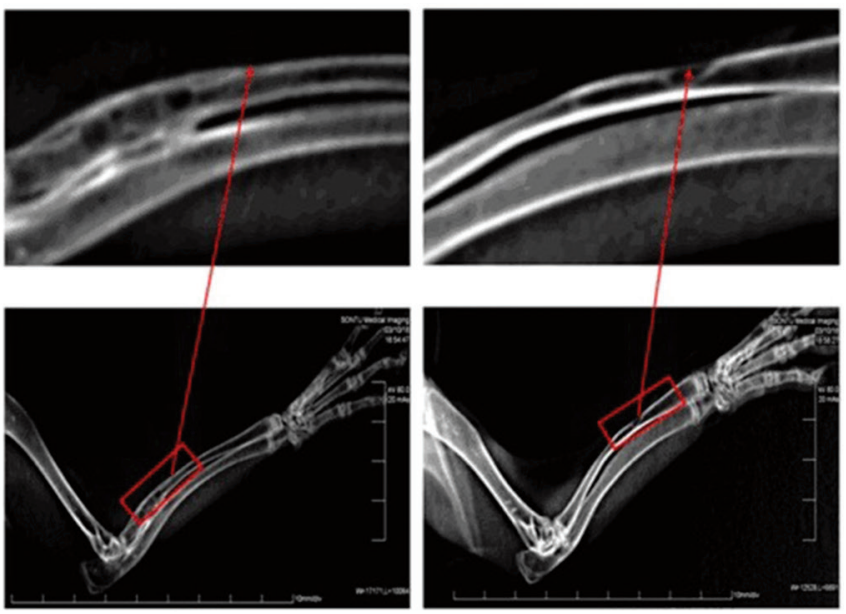

PLGA

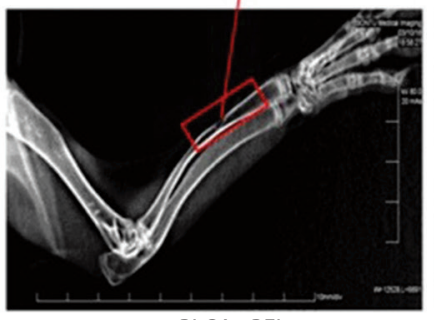

PLGA@PEI

B
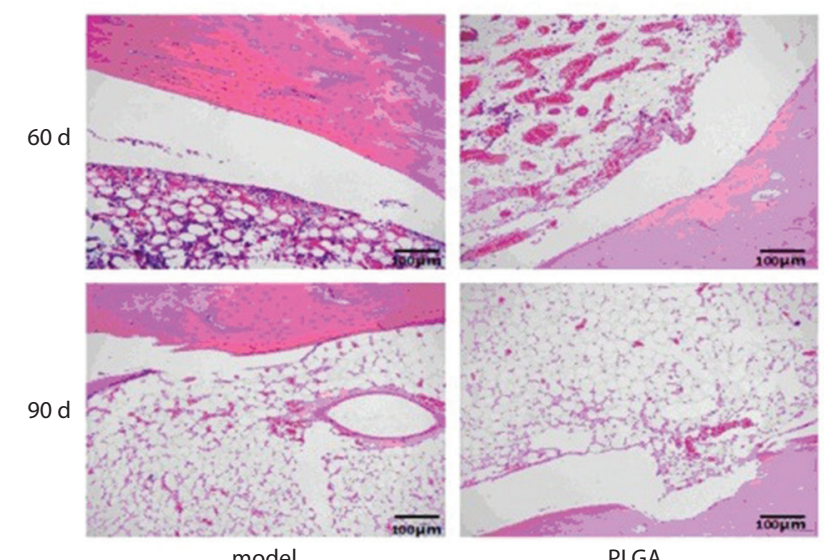

PLGA
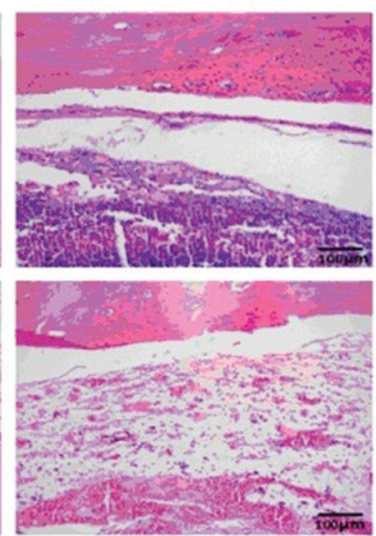

PLGA@PE

C
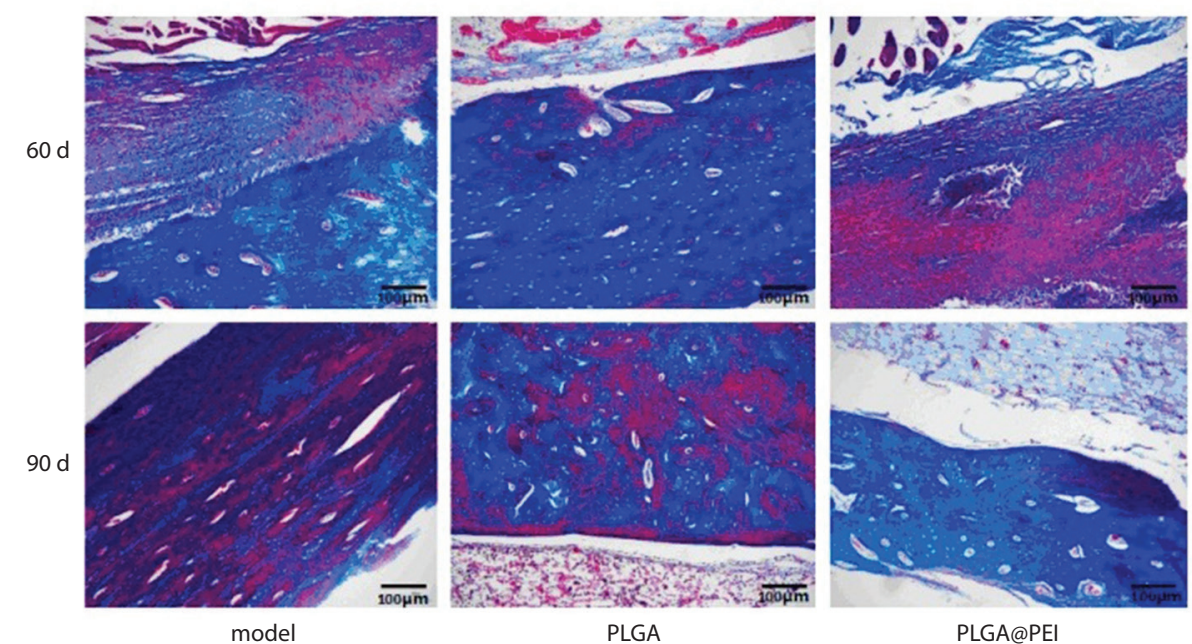

PLGA

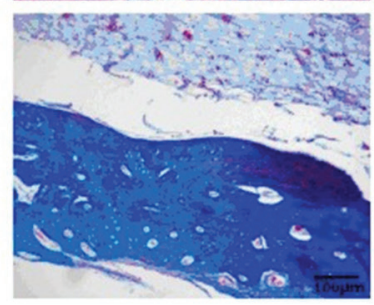

PLGA@PEI

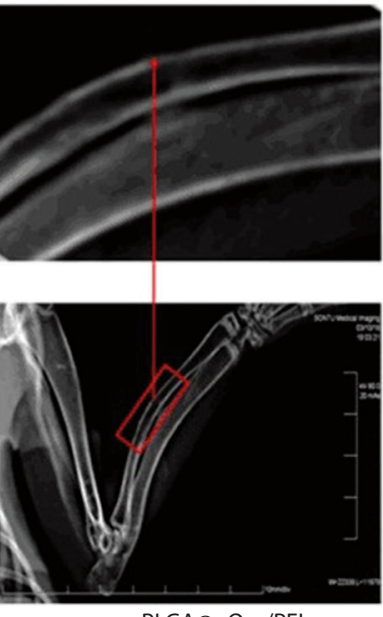

PLGA@pOsx/PEI

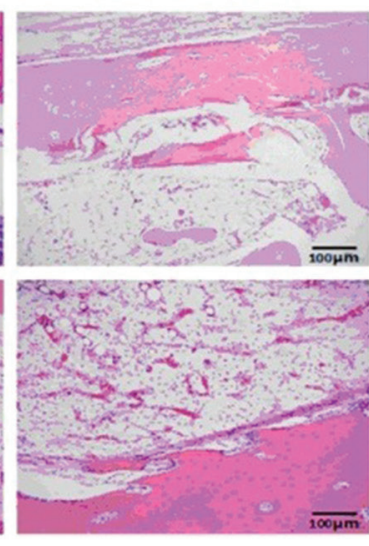

PLGA@pOsx/PE
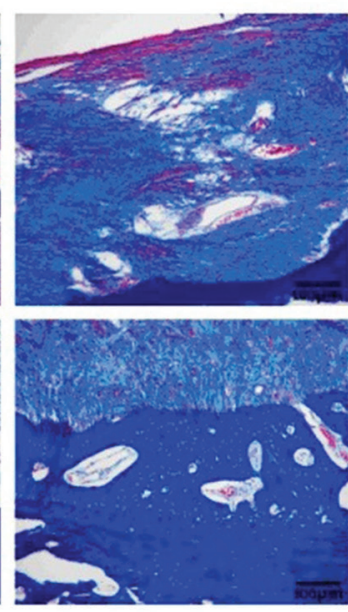

PLGA@pOsx/PEI

Fig. 5.PLGA@pOsx/PEl microspheres promoted osteogenesis in vivo

A - H-ray results; $\mathrm{B}$ - H\&E staining results; C - Masson staining results.

\section{PLGA@pOsx/PEI microspheres promoted osteogenesis in vivo}

As shown in Fig. 5A, there were significant bone defects in the model group, the PLGA group and the PLGA@PEI group. The enlarged area was obviously rough and uneven. In the PLGA@pOsx/PEI group, the boundary between the defect and the autogenous bone was blurred, and the enlarged area was smooth and uniform.

As shown in Fig. 5B, the model group, the PLGA group and the PLGA@PEI group were loosely connected at 60 and 90 days of experiment with intermittent spaces between them. In the PLGA@pOsx/PEI group, new bone was formed, and the defect tissue was closely bound to the surrounding bone. 

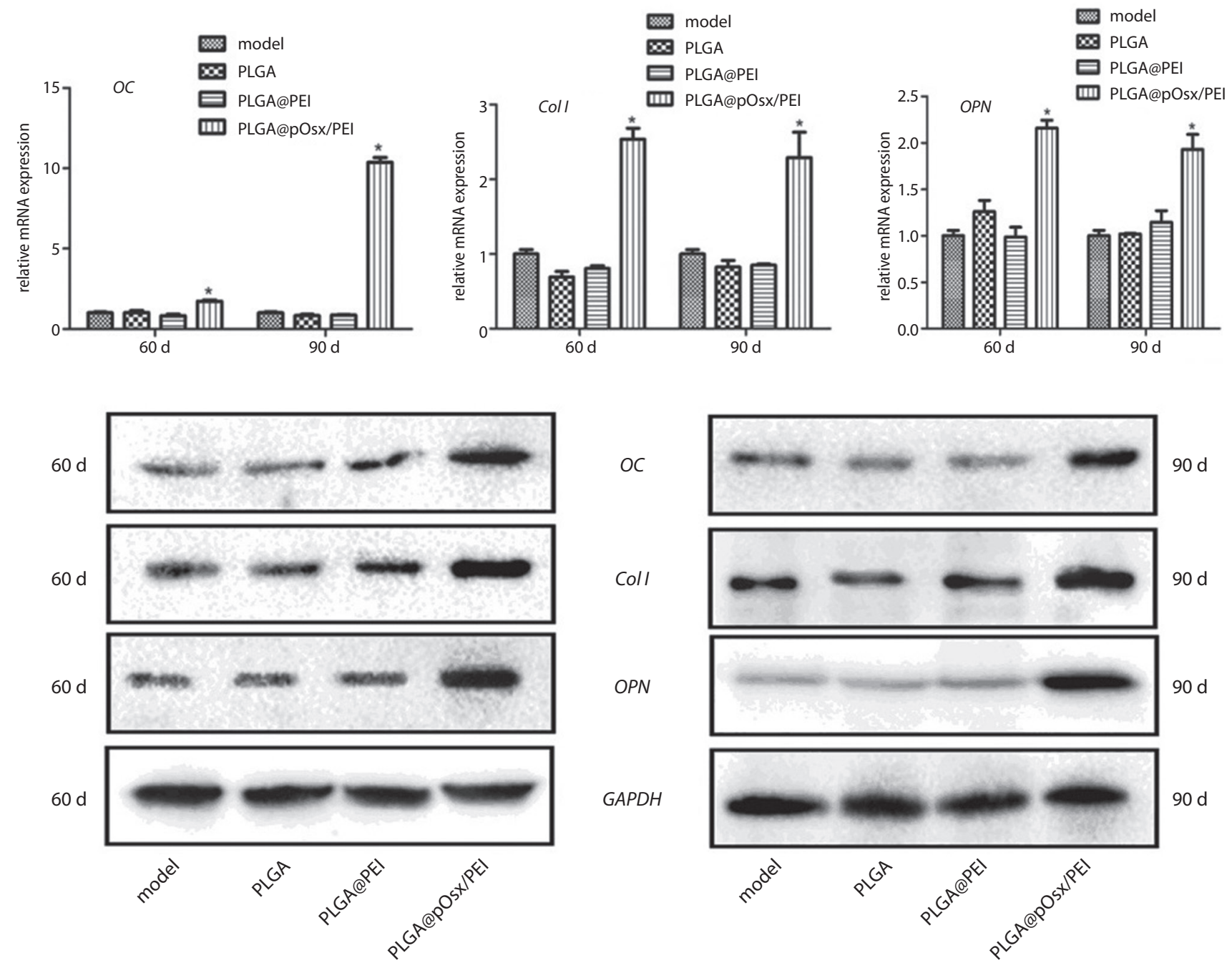

Coll

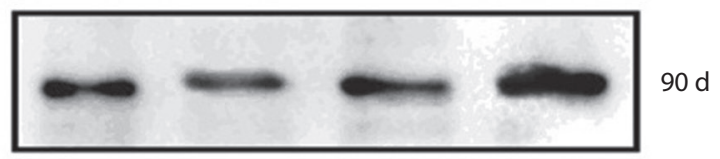

OPN

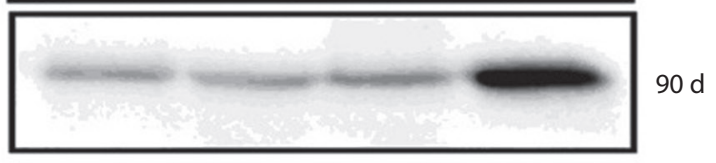

GAPDH
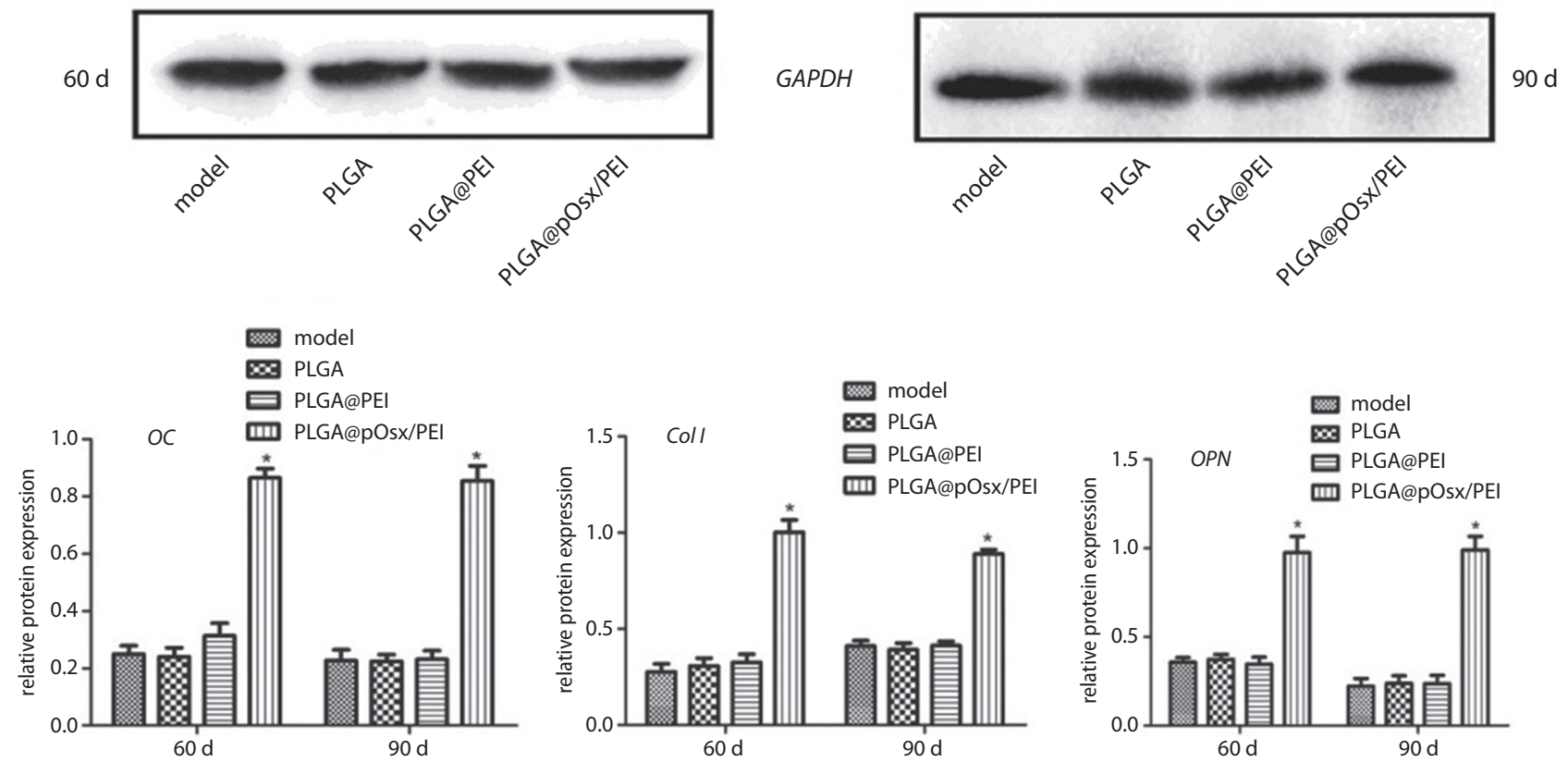

Fig. 6. The effect of PLGA@pOsx/PEl on the expression of COL-1, OPN and OC in vivo

Compared with that of the model group, the mRNA expression of OC, Col-1 and OPN in the PLGA@pOsx/PEl group increased significantly at 60 ( $p=0.041$, $p=0.023, p=0.038$ respectively) and 90 days $(p=0.003, p=0.020, p=0.037$, respectively), the protein expressions of OC, Col-1 and OPN in the PLGA@ POsx/PEl group also increased significantly at $60(p=0.025, p=0.031, p=0.034$, respectively) and 90 days $(p=0.024, p=0.022, p=0.036$, respectively).

Figure $5 \mathrm{C}$ shows that in the model group, the PLGA and the PLGA@PEI groups, fibroblasts proliferated and collagen fibers increased but were arranged irregularly at 60 and 90 days of experiment. In the PLGA@pOsx/PEI group, fibroblasts proliferated, collagen fibers increased, the arrangement tended to be regular, and inflammatory cells decreased.

\section{PLGA@pOsx/PEl promoted Col-1, $\mathrm{OPN}$ and $\mathrm{OC}$ expression in vivo}

As shown in Fig. 6, the mRNA expression of OC, Col-1 and OPN in the PLGA@pOsx/PEI group was significantly higher than those in the model group at $60(\mathrm{p}=0.041$, $\mathrm{p}=0.023, \mathrm{p}=0.038$, respectively) and 90 days $(\mathrm{p}=0.003$, 
$\mathrm{p}=0.020, \mathrm{p}=0.037$, respectively). The protein expressions of OC, Col-1 and OPN in PLGA@pOsx/PEI group were also significantly higher than those in model group at 60 ( $\mathrm{p}=0.025, \mathrm{p}=0.031, \mathrm{p}=0.034$, respectively) and 90 days $(\mathrm{p}=0.024, \mathrm{p}=0.022, \mathrm{p}=0.036$, respectively).

\section{Discussion}

Bone defects caused by acute trauma, congenital deformity, benign and malignant tumors, bone infection and nonunion of fracture need to be repaired surgically. Bone substitute materials include synthetic scaffolds, natural bio-derived scaffolds, and composite scaffolds. The tissue engineering scaffolds made of single scaffolds often have some unavoidable defects, cannot meet the normal physiological needs of the human body, and limit their clinical application.8,29 The PLGA@pOsx/PEI material used in this study has a high gene transfection rate and can release the pOsx/PEI nanoparticles slowly in the local bone defect for a longer time.

In this study, PLGA@PEI material was used to wrap Osx in cells and animals, and Osx expression in cells and animals was significantly increased. These results suggested that this method had a high gene transfection rate. There was no significant difference in cell proliferation and cell cycle between groups. Therefore, the material had good biocompatibility and no toxic effect on the growth and proliferation of MC3T3-E1 osteoblasts.

The synthesis and secretion of ALP is an important marker of osteoblast differentiation and maturation and has been widely used as a marker of osteoblast identification. It has the function of hydrolyzing organic phosphoric acid and can increase local phosphate concentration, degrade calcification inhibitors in microenvironment, combine and transport calcium ions, and start the calcification process. ${ }^{30}$ This study showed that ALP activity was significantly increased in the PLGA@pOsx/PEI group. The overexpression of Osx not only promotes the differentiation and mineralization of bone marrow stromal stem cells into osteoblasts, but also increases ALP activity and mineralized nodule formation in muscle satellite cells. ${ }^{31}$ Our result suggested that Osx had a promoting effect on directional osteogenic differentiation.

Osteocalcin (OC), osteopontin (OPN) and collagen I (COL-I) are important osteoblast-related cytokines secreted and synthesized by osteoblasts, which can be used as indicators for evaluating the functional status of osteoblasts. Collagen I provides a framework for cell adhesion and calcium deposition, and the COL-I expression in cells can be used as an index for evaluating the functional status of osteoblasts. ${ }^{32}$ Osteocalcin is an extracellular matrix protein and an important osteogenic factor for maintaining bone matrix calcification and normal mineralization rate. Osteocalcin is one of the markers of matrix mineralization of osteoblasts and is instrumental in maintaining normal mineralization rate and calcification process of bone matrix. ${ }^{33}$ Osteopontin is an important osteogenic factor in maintaining the mineralization and absorption of bone matrix, participating in the process of bone formation and bone remodeling, and also a marker of osteoblasts. Osteopontin can be synthesized and secreted by many kinds of cells. It is an important chemokine in cell adhesion in vivo. It participates in many metabolic processes, such as bone metabolism, invasion and metastasis of tumors, inflammatory reaction and immunity. It can stimulate the proliferation and calcification of osteoblasts. ${ }^{34-36}$ Our study found that PLGA@pOsx/PEI could promote the expression of $O C, O P N$ and $C O L-I$. These results suggested that Osx could promote osteoblast differentiation by affecting the expression of characteristic proteins related to osteoblast differentiation. The results of X-ray and histopathological findings were consistent with the above conclusions. These results suggested that the overexpression of $O s x$ promoted new bone formation.

\section{Conclusions}

The study confirmed that the overexpression of Os $x$ could promote the expression of OC, OPN and COL-I. PLGA@pOsx/PEI can be used as a material for repairing bone defects, which could promote bone formation and provide a theoretical and practical basis for further clinical application.

\section{ORCID iDs}

Jingtang Li (D) https://orcid.org/0000-0003-2652-7161

Guanxiang Liao (D) https://orcid.org/0000-0003-4010-9062

Zhisheng Long (D) https://orcid.org/0000-0001-6239-0591

Peng Qiu (D) https://orcid.org/0000-0003-0289-0134

Linghua Ding (D) https://orcid.org/0000-0002-4040-9519

Long Xiong (D) https://orcid.org/0000-0003-1674-9174

\section{References}

1. Dimitriou $R$, Jones $E$, McGonagle $D$, et al. Bone regeneration: Current concepts and future directions. BMCMed. 2011;9:66. doi:10.1186/17417015-9-66

2. Athanasiou VT, Papachristou DJ, Panagopoulos A, et al. Histological comparison of autograft, allograft-DBM, xenograft, and synthetic grafts in a trabecular bone defect: An experimental study in rabbits. Med Sci Monit. 2010;16(1):BR24-BR31.

3. Brydone AS, Meek D, Maclaine S. Bone grafting, orthopaedic biomaterials, and the clinical need for bone engineering. Proc Inst Mech Eng H. 2010;224(12):1329-1343. doi:10.1243/09544119JEIM770

4. Oryan A, Alidadi S, Moshiri A, et al. Bone regenerative medicine: classic options, novel strategies, and future directions. J Orthop Surg Res. 2014;9(1):18. doi:10.1186/1749-799X-9-18

5. Amini AR, Laurencin CT, Nukavarapu SP. Bone tissue engineering: Recent advances and challenges. Crit Rev Biomed Eng. 2012;40(5): 363-408.

6. Liu M, Zeng X, Ma C, et al. Injectable hydrogels for cartilage and bone tissue engineering. Bone Res. 2017;5:17014. doi:10.1038/boneres. 2017.14.

7. Zhang Y, Ma W, Zhan Y, et al. Nucleic acids and analogs for bone regeneration. Bone Res. 2018;6:37. doi:10.1038/s41413-018-0042-7

8. Yi H, Ur Rehman F, Zhao C, et al. Recent advances in nano scaffolds for bone repair. Bone Res. 2016;4:16050. doi:10.1038/boneres.2016.50 
9. Bhattacharjee P, Kundu B, Naskar D, et al. Silk scaffolds in bone tissue engineering: An overview. Acta Biomater. 2017;63:1-17. doi:10.1016/j. actbio.2017.09.027

10. Wubneh A, Tsekoura EK, Ayranci C, et al. Current state of fabrication technologies and materials for bone tissue engineering. Acta Biomater. 2018;80:1-30. doi:10.1016/j.actbio.2018.09.031

11. Carreira AC, Lojudice FH, Halcsik E, et al. Bone morphogenetic proteins: Facts, challenges, and future perspectives. J Dent Res. 2014;93(4): 335-345. doi:10.1177/0022034513518561

12. Ronga M, Fagetti A, Canton G, et al. Clinical applications of growth factors in bone injuries: Experience with BMPs. Injury. 2013;44(Suppl1): S34-S39. doi:10.1016/S0020-1383(13)70008-1

13. Nakashima K, Zhou X, Kunkel G, et al. The novel zinc finger-containing transcription factor osterix is required for osteoblast differentiation and bone formation. Cell. 2002;108(1):17-29.

14. Liang GS, Chen WC, Yin CC, et al. Effect of total ravonoids of herba epimedium on BMP-2/RunX2/OSX signaling pathway during osteogenic differentiation of bone marrow mesenchymal stem cells. Zhongguo Zhong Xi Yi Jie He Za Zhi. 2016;36(5):614-618.

15. Yang G, Yuan G, MacDougall M, et al. BMP-2 induced Dspp transcription is mediated by DIx3/Osx signaling pathway in odontoblasts. Sci Rep. 2017;7(1):10775. doi:10.1038/s41598-017-10908-8

16. Cooley MA, Harikrishnan K, Oppel JA, et al. Fibulin-1 is required for bone formation and Bmp-2-mediated induction of Osterix. Bone. 2014;69:30-38. doi:10.1016/j.bone.2014.07.038

17. Sinha KM, Zhou X. Genetic and molecular control of osterix in skeletal formation. J Cell Biochem. 2013;114(5):975-984. doi:10.1002/jcb.24439

18. Feng JQ, Zhang H, Qin C. Letter to the Editor: Osterix regulates tooth root formation in a site-specific manner. J Dent Res. 2015;94(9):1326. doi:10.1177/0022034515593744

19. Mizoguchi T, Pinho S, Ahmed J, et al. Osterix marks distinct waves of primitive and definitive stromal progenitors during bone marrow development. Dev Cell. 2014;29(3):340-349. doi:10.1016/j.devcel. 2014.03.013

20. Yin H, Kanasty RL, Eltoukhy AA, et al. Non-viral vectors for gene-based therapy. Nat Rev Genet. 2014;15(8):541-555. doi:10.1038/nrg3763

21. Ibraheem D, Elaissari A, Fessi H. Gene therapy and DNA delivery systems. Int J Pharm. 2014;459(1-2):70-83. doi:10.1016/j.ijpharm.2013. 11.041

22. Xun MM, Liu YH, Guo Q, et al. Low molecular weight PEl-appended polyesters as non-viral gene delivery vectors. Eur J Med Chem. 2014; 78:118-125. doi:10.1016/j.ejmech.2014.03.050

23. Yan $X$, Zhang $Y$, Zhang $H$, et al. Amphiphilic polyethylenimine (PEI) as highly efficient non-viral gene carrier. Org Biomol Chem. 2014; 12(12):1975-1982. doi:10.1039/c3ob42279h
24. Shen J, Xu R, Mai J, et al. High capacity nanoporous silicon carrier for systemic delivery of gene silencing therapeutics. ACS Nano. 2013; 7(11):9867-9880. doi:10.1021/nn4035316

25. Elsabahy M, Nazarali A, Foldvari M. Non-viral nucleic acid delivery: Key challenges and future directions. Curr Drug Deliv. 2011;8(3):235-244.

26. Patnaik S, Gupta KC. Novel polyethylenimine-derived nanoparticles for in vivo gene delivery. Expert Opin Drug Deliv. 2013;10(2):215-228. doi:10.1517/17425247.2013.744964

27. Kempen $\mathrm{DH}, \mathrm{Lu} \mathrm{L}$, Hefferan $T E$, et al. Retention of in vitro and in vivo BMP-2 bioactivities in sustained delivery vehicles for bone tissue engineering. Biomaterials. 2008;29(22):3245-3252. doi:10.1016/j.biomaterials.2008.04.031

28. Qiao C, Zhang K, Jin H, et al. Using poly(lactic-co-glycolic acid) microspheres to encapsulate plasmid of bone morphogenetic protein 2/ polyethylenimine nanoparticles to promote bone formation in vitro and in vivo. Int J Nanomedicine. 2013;8:2985-2995. doi:10.2147/IJN. S45184

29. Mao C, Pan W, Shao X, et al. The clearance effect of tetrahedral dna nanostructures on senescent human dermal fibroblasts. ACS Appl Mater Interfaces. 2019;11(2):1942-1950. doi:10.1021/acsami.8b20530

30. Daltaban O, Saygun I, Bal B, et al. Gingival crevicular fluid alkaline phosphatase levels in postmenopausal women: effects of phase I periodontal treatment. J Periodontol. 2006;77(1):67-72. doi:10.1902/ jop.2006.77.1.67

31. Ding LZ, Teng X, Zhang ZB, et al. Mangiferin inhibits apoptosis and oxidative stress via BMP2/Smad-1 signaling in dexamethasoneinduced MC3T3-E1 cells. Int J Mol Med. 2018;41(5):2517-2526. doi:10. 3892/ijmm.2018.3506

32. Shen H, Wang J, Min J, et al. Activation of TGF-beta1/alpha-SMA/Col I profibrotic pathway in fibroblasts by galectin-3 contributes to atrial fibrosis in experimental models and patients. Cell Physiol Biochem. 2018;47(2):851-863. doi:10.1159/000490077

33. Brady KP, Dushkin H, Fornzler D, et al. A novel putative transporter maps to the osteosclerosis (oc) mutation and is not expressed in the OC mutant mouse. Genomics. 1999;56(3):254-261. doi:10.1006/geno. 1998.5722

34. Martins CM, de Azevedo Queiroz IO, Ervolino E, et al. RUNX-2, OPN and OCN expression induced by grey and white mineral trioxide aggregate in normal and hypertensive rats. Int Endod J. 2018;51(6):641-648. doi:10.1111/iej.12876

35. Byeon H, Lee SD, Hong EK, et al. Long-term prognostic impact of osteopontin and Dickkopf-related protein 1 in patients with hepatocellular carcinoma after hepatectomy. Pathol Res Pract. 2018;214(6): 814-820. doi:10.1016/j.prp.2018.05.002

36. Zhang Q, Lin S, Zhang T, et al. Curved microstructures promote osteogenesis of mesenchymal stem cells via the RhoA/ROCK pathway. Cell Prolif. 2017;50(4):e12356. doi:10.1111/cpr.12356 